\title{
Psychological issues in football officiating: An interview study with top-level referees
}

\author{
Urs Schnyder ${ }^{1, *}$ \& Ernst-Joachim Hossner ${ }^{1}$ \\ 1 Institute of Sport Science, University of Bern, Bern, Switzerland \\ * Corresponding author: Institute of Sport Science, University of Bern, Bremgartenstrasse 145, CH-3012 Bern, Switzerland, \\ Tel: +4131 6315167, Fax: +41316315169 \\ Email: urs.schnyder@ispw.unibe.ch
}

\section{ORIGINAL ARTICLE}

\section{Article History:}

Received $15^{\text {th }}$ March 2016

Accepted 09th August 2016

Published $27^{\text {th }}$ September 2016

Handling Editors:

Günter Amesberger,

University of Salzburg, Austria

Sabine Würth,

University of Salzburg, Austria

Editor-in-Chief:

Martin Kopp

University of Innsbruck, Austria

Reviewers:

Markus Raab

DSHS Köln, Germany

Reviewer 2: anonymous

\section{ABSTRACT}

The present study aims on the identification of problems in the practice of top-level football refereeing. For this purpose, semi-structured interviews were conducted to collect data from 23 European elite referees. Through inductive content analysis, seven higher-order themes emerged: (1) descriptive, (2) characteristics of a good elite referee, (3) difficulties in decision-making, (4) pre-match preparation, (5) communication through headset, (6) decision-making, and (7) decision-making training. On the one hand, the findings underline the practical relevance of existing scientific research; on the other hand, the relevance of some areas of research, for instance, on the role of biases, is questioned by the interviewees' statements. A particular need for further research could be revealed regarding the development, optimisation, or evaluation of (1) the pre-match preparation, (2) supporting technical devices, (3) innovative training tools for decision-making, (4) the within-team communication, and (5) complementary methods such as mental practice.

Keywords:

association football - expert performance - psychological characteristics - refereeing team communication - visual perception

Citation:

Schnyder, U., \& Hossner, E.-J. (2016). Psychological issues in football officiating: An interview study with top-level referees.

Current Issues in Sport Science, 1:004. doi: 10.15203/CISS_2016.004

\section{Introduction}

Officials take a vital role in almost every competition-oriented game sport. Especially in professional sports, referee's decisions are often controversially discussed by the involved team or by the media. Not least for this reason an interesting area of research has emerged over the recent years with respect to sports officiating (MacMahon \& Plessner, 2008). Apart from a considerable number of studies regarding the physiological condition of officials (e.g., Castagna, Abt, \& D'Ottavio, 2007; Krustrup et al., 2009; Weston, Castagna, Helsen, \& Impellizzeri, 2009), less research has been conducted on the decision-making process itself. Consequently, research on the psychologi- cal facets of referees' performance seems to be a particularly growing field in science on sports refereeing (e.g., MacMahon \& Plessner, 2013; MacMahon et al., 2014; Mascarenhas, O'Hare, Plessner, \& Button, 2006). In this regard, Plessner and MacMahon (2013) have identified three main types of officials depending on the amount of interaction with athletes and the number of cues they have to consider: Interactors, like football referees, have a high interaction level and a lot of cues to process (e.g., in rugby: Cunningham, Mellick, Mascarenhas, \& Fleming, 2012; Mascarenhas, Collins, \& Mortimer, 2005; Mellick, Fleming, Bull, \& Laugharne, 2005; Mellick, Fleming, \& Davies, 2007); sport monitors (e.g., gymnastics judges) have low physical demands but a large number of cues to monitor (e.g. in gymnastics: Bard, 
Fleury, Carrière, \& Hallé, 1980; Plessner \& Schallies, 2005); and reactors (e.g., line judges in tennis) have low physical demands and a low number of cues to observe (e.g. in tennis: Whitney, Wurnitsch, Hontiveros, \& Louie, 2008). Although parallels can be drawn within the three main types of officials, the requirements for each referee are different, which leads to the scientific interest to identify particular officiating issues in a specific sports. For this reason, the main focus of the research at hand has been laid on the reconstruction of particular issues in football refereeing. From a scientific perspective, football refereeing has been especially examined with respect to (a) visual perception, (b) judgement biases, (c) performance enhancement, or (d) further aspects of the decision-making process.

(a) Visual perception plays an important role with regard to the quality of decision-making. The head referee takes 137 observable decisions during a single match, whereof $64 \%$ are based on communication within the referee team (Helsen \& Bultynck, 2004). Regarding basic visual skills that underlie these decisions, it could be shown that expert football referees outperform novices in visual skills such as accommodation (cycles/minute), peripheral vision $(\mathrm{cm})$, saccadic eye movements (numbers/ minute), and speed of recognition (number of redrawn geometric shapes per minute; Ghasemi, Momeni, Jafarzadehpur, Rezaee, \& Taheri, 2011; Ghasemi, Momeni, Rezaee, \& Gholami, 2009). With respect to gaze behaviour, it could be proven that expert assistant referees do not use gaze strategies that differ from those used by near-experts, although they are able to judge offside situations more accurately (Catteeuw, Helsen, Gilis, Van Roie, \& Wagemans, 2009; see also Schnyder, Koedijker, Kredel, \& Hossner, 2014). Apart from these results, there is an ongoing discussion on whether the positioning of referees and assistant referees is crucial for decision-making. In this respect, for the head referee, Mallo, Frutos, Juárez, and Navarro (2012) were able to demonstrate an optimal distance to the event, whereas Oliveira, Orbetelli, and Barros Neto (2011) presented conflicting results. Furthermore, for judging offside, there has been an intense debate between proponents of the opticalerror hypothesis stating that misalignments of the assistant referee to the offside line lead to systematic errors (Oudejans et al., 2000, 2005) and the opposing party whose proponents prefer an alternative explanation that is rooted in the so-called flash-lag effect and the assumption that the current position of the players is misperceived due to their current velocity at the "flash-like" point in time when the ball is passed to the attacker (Baldo, Ranvaud, \& Morya, 2002; Barte \& Oudejans, 2012; Catteeuw, Gilis, García-Aranda, et al., 2010; Catteeuw, Gilis, Wagemans, \& Helsen, 2010a; Gilis, Helsen, Catteeuw, \& Wagemans, 2008; Gilis, Helsen, Catteeuw, Van Roie, \& Wagemans, 2009; Helsen, Gilis, \& Weston, 2006).

(b) Quite obviously, decision-making is the core business of football referees. From a scientific perspective, this issue has been approached by Plessner and Haar (2006) from a social cognition perspective showing that misjudgements can happen over different stages of information processing and may refer to perception, categorisation, prior knowledge, as well as information integration. Perception-related research has already been discussed previously. Concerning the task of categorisation, Unkelbach and Memmert (2008) revealed that football referees give less yellow cards in the initial phase of a game as it should be statistically expected. Obviously, referees first need to get a feel for the game before they are ready to impose hard sanctions. Regarding prior knowledge, Jones, Paull, and Erskine (2002) found an effect of an aggressive reputation of a team on the referee's decision. Furthermore, the memory aspect of prior knowledge is underlined by evidence regarding the specific effects of the colour of players' shirts (Frank \& Gilovich, 1988). Concerning information integration, as information is often not available to a sufficient degree, referees learn to use additional or alternative cues for their decisions, for instance, crowd noise (Dohmen, 2008; Downward \& Jones, 2007; Nevill, Balmer, \& Williams, 2002; Page \& Page, 2010; Unkelbach \& Memmert, 2010). This behaviour might also explain the wellestablished phenomenon of home advantage (Boyko, Boyko, \& Boyko, 2007; Buraimo, Forrest, \& Simmons, 2010; Dawson \& Dobson, 2010; Dawson, Dobson, Goddard, \& Wilson, 2007; Goumas, 2014; Johnston, 2008; Sutter \& Kocher, 2004;). Besides those external cues, it could also be shown that referees are influenced by their own prior decisions leading, for instance, to compensating tendencies in penalty-kick judgements (Plessner \& Betsch, 2001; Schwarz, 2011).

(c) Regarding performance enhancement by means of on-field interventions, referee-specific research seems still to be in its infancy (MacMahon, Helsen, Starkes, \& Weston, 2007). However, it could be shown so far that motor and perceptual experience has a positive effect on decision-making on deceptive movements in football (Pizzera \& Raab, 2012a; Renden, Kerstens, Oudejans, \& Cañal-Bruland, 2014). Furthermore, Pizzera and Raab (2012b) could show that watching games without having to judge them is positively linked to high performance quality. Therefore, "soccer referees' performance may be enhanced by watching a great amount of games over many years" (Pizzera \& Raab, 2012b, p. 71). For off-field training, it was found that video training with feedback is very effective for improving offside decisions (Catteeuw, Gilis, Jaspers, Wagemans, \& Helsen, 2010; Catteeuw, Gilis, Wagemans, \& Helsen, 2010b; Put, Wagemans, Spitz, Williams, \& Helsen, 2015) as well as foul decisions (Brand, Schweizer, \& Plessner, 2009; Schweizer, Plessner, Kahlert, \& Brand, 2011). The fact that those off-field improvements might positively transfer to the on-field situation was demonstrated by Put, Wagemans, Jaspers, and Helsen (2013).

(d) In the branch of psychological research on football refereeing, some further topics can be identified that have received only minor attention up to now. This statement particularly applies to the issues of psychological demands and strengths as characteristics like self-confidence, self-analysis, and selfdevelopment that seem to be central to successfully officiating football games (Mason \& Lovell, 2000; Philippe, Vallerand, Andrianarisoa, \& Brunel, 2009; Wolfson \& Neave, 2007). The same seems to be true for capacities regarding team interaction and game management that are also described as vital qualities 
of excellent football referees (Slack, Maynard, Butt, \& Olusoga, 2013). However, respective research, especially on the internal communication through headset, is widely entirely.

Summing up, over recent years, an increasing body of sport scientific work aiming on psychological aspects of officiating in football can be identified. The rationale behind these studies can generally be characterized as pursuing a "from theory to practice" strategy. This means that the identification of potential problems is rooted in scientific theories in the first instance before it is empirically checked whether these problems can be proven relevant also under the applied conditions of the practical situation. As demonstrated in the decades of successful research, this strategy undoubtedly leads to absolutely valuable results. Nonetheless, it also should be recognised that this approach is inevitably infected with the risks that (a) crucial practice problems may be missed as they are not reflected by the scientific theory and that, as a further consequence, (b) the recommendations derived from the empirical results may misfit the actual practice demands.

A good example for such an imperfect fit between concept-driven research and practical derivations can be found in the model for fair referee assignments proposed by Yavuz, İnan, and Fığlalı (2008). This model is based on a search procedure in which each football referee within a squad is treated equally such that each referee would be assigned to the same number of matches over a season. Although this procedure might actually result in the fairest possible solution from a scientific standpoint, the model completely ignores further constraints imposed by practice. Besides problems of unforeseeable injuries, these constraints, among others, refer to the fact that experienced referees should be assigned to "hard" matches that are decisive for the championship, the relegation, or the qualification for international events, whereas young referee talents should be spared and preferably be allocated to easier matches. Furthermore, to support their qualifications for international tournaments, each national association is interested in letting its most promising candidates referee the most prestigious matches over the season. As a consequence of those "real-world" constraints, for the practice of referee assignment, the value of the scientific model proposed by Yavuz at al. (2008) is considerably limited. Hence, before the first steps of model development were taken, it would have been advisable to consult experienced practitioners to finally end up with a model that features a better chance of being accepted in the world of sports.

As a matter of course, it cannot be inferred from the just sketched risks that theory-driven research without previous consultancy of sports experts necessarily results in useless recommendations for practice. However, it can definitely be asserted that such a consultancy is helpful at least to check whether the research question at hand as well as derived practical implications are assessed by experienced practitioners as being relevant from an applied perspective. Beyond, as long as innovative training opportunities for referees are desired (Gilis et al., 2009), it is important to obtain a deeper understanding of this research field, especially from the perspective of practitioners, to generate training tools to enhance the performance of officials. Hence, the present project aimed on the reconstruction of subjective theories of top-level football referees on the relevance of the psychological aspects of officiating, in particular, regarding (a) visual perception, (b) judgement biases, (c) performance enhancement, and (d) further topics such as psychological strengths, team interaction, and game management.

\section{Methods}

\section{Participants}

In total, 23 international referees from 17 European countries (R01-R23; for details, see Table 1) agreed to participate in the study (all male). The majority was qualified for the UEFA elite group ( $n=19 ; M_{\text {age }}=39.8$ years; $S D=2.4$ years $)$ and the rest for the UEFA first group ( $n=4 ; M_{\text {age }}=33.0$ years; $S D=2.9$ years). Eight participating referees had been nominated for the FIFA World Cup 2010 in South Africa or 2014 in Brazil. The elitegroup participants had international experience as FIFA referees for 9.1 years on average $(S D=2.4$ years) and 24.5 years $(S D=$ 3.1 years) of overall experience in football refereeing. The firstgroup participants were on the FIFA list for 6.8 years on average $(S D=3.0$ years), with an overall refereeing experience of 18.3 years ( $S D=1.9$ years). Given that, as of February 2015, from a total of 272 international officials ranked in four performance groups (elite, first, second, and third) only 68 were in the first category and just 22 in the elite group, the interviewees can be considered to represent the best referees in Europe.

The study was conducted in accordance with the Declaration of Helsinki. Hence, the participation was voluntary and the participants could withdraw their consent at any time. As in the report at hand, it may be of interest to be able to assign verbatimcited phrases to particular interviewees; in addition to informed consent, the referees were asked whether they would agree to be cited in a non-anonymised way. All interviewees explicitly declared their consent to this procedure, except one referee, who wanted to stay anonymous (R08). Moreover, whenever a referee will be cited in the following, a further permission has been given by the respective referee for the verbatim citation of this particular phrase.

\section{Interview guide}

Methodologically, the appropriate way to approach the referee's first-person beliefs is the conduct of qualitative interviews. Hence, a semi-structured interview guide was developed that contained open-ended and non-leading questions (Patton, 2002) to explore relevant expert knowledge. The interview guide was checked in the course of four test interviews, which were also held with top European referees (see Table 1, marked by asterisks). On this basis, the guide could be revised by the research group consisting of the first author and an assistant researcher, both of them experienced in gathering and analys- 
Table 1: Demographics of Participants R01-R23 (as of February 2015)

\begin{tabular}{|c|c|c|c|c|c|c|}
\hline Code & Name & Country & $\begin{array}{l}\text { REF } \\
\text { since }\end{array}$ & $\begin{array}{l}\text { FIFA } \\
\text { since }\end{array}$ & $\begin{array}{l}\text { UEFA } \\
\text { ranking }\end{array}$ & Achievements \\
\hline $\mathrm{R} 01^{*}$ & Cüneyt Cakir & TUR & 1994 & 2006 & Elite & $\begin{array}{l}\text { FIFA WC 2014, U-20 FIFA WC 2013, EURO } 2012 \text { U-20 FIFA WC 2011, } \\
\text { U-21 EURO 2009, U-19 EURO 2007, UEFA CL, UEFA EL }\end{array}$ \\
\hline R02 & Jonas Eriksson & SWE & 1988 & 2002 & Elite & $\begin{array}{l}\text { FIFA WC 2014, U-20 FIFA WC 2013, EURO 2012, U-19 EURO 2006, } \\
\text { UEFA CL, UEFA EL }\end{array}$ \\
\hline R03 & Viktor Kassai & HUN & 1990 & 2003 & Elite & $\begin{array}{l}\text { U-20 FIFA WC 2013, EURO 2012, FIFA WC 2010, U-17 FIFA WC 2009, } \\
\text { Summer Olympics 2008, U-20 FIFA WC 2007, U-19 EURO 2005, UEFA } \\
\text { CL, UEFA EL }\end{array}$ \\
\hline R04 & Björn Kuipers & NED & 1989 & 2006 & Elite & $\begin{array}{l}\text { FIFA WC 2014, Confederations Cup 2013, EURO 2012, U-21 EURO } \\
\text { 2009, UEFA CL, UEFA EL }\end{array}$ \\
\hline R05 & Milorad Mazic & SRB & 1996 & 2009 & Elite & $\begin{array}{l}\text { FIFA WC 2014, U-20 FIFA WC 2013, U-21 EURO 2011, U-19 EURO } \\
\text { 2009, UEFA CL, UEFA EL }\end{array}$ \\
\hline R08 & Anonymous & - & - & - & - & $\mathrm{N} / \mathrm{A}$ \\
\hline R09 & Damir Skomina & SVN & 1992 & 2003 & Elite & $\begin{array}{l}\text { U-20 FIFA WC 2013, EURO 2012, Summer Olympics 2008, U-21 } \\
\text { EURO 2007, U-19 EURO 2005, UEFA CL, UEFA EL }\end{array}$ \\
\hline $\mathrm{R} 10$ & Craig Thomson & $\mathrm{SCO}$ & 1988 & 2003 & Elite & U-17 FIFA WC 2013, EURO 2012, U-21 EURO 2007, UEFA CL, UEFA EL \\
\hline $\mathrm{R} 11$ & William Collum & $\mathrm{SCO}$ & 1993 & 2006 & Elite & U-20 FIFA WC 2011, U-19 EURO 2008, UEFA CL, UEFA EL \\
\hline $\mathrm{R} 12$ & Mark Clattenburg & ENG & 1990 & 2006 & Elite & $\begin{array}{l}\text { U-17 FIFA WC 2013, Summer Olympics 2012, U-20 FIFA WC 2011, } \\
\text { UEFA CL, UEFA EL }\end{array}$ \\
\hline $\mathrm{R} 13$ & Pavel Královec & CZE & 1993 & 2005 & Elite & $\begin{array}{l}\text { U-17 FIFA WC 2013, Summer Olympics 2012, U-17 FIFA WC 2011, } \\
\text { U-19 EURO 2007, UEFA CL, UEFA EL }\end{array}$ \\
\hline R18 & Deniz Aytekin & GER & 1995 & 2011 & Elite & UEFA CL, UEFA EL \\
\hline R19 & $\begin{array}{l}\text { David Fernández } \\
\text { Borbalán }\end{array}$ & ESP & 1986 & 2010 & Elite & UEFA CL, UEFA EL \\
\hline $\mathrm{R} 20^{*}$ & Ivan Bebek & CRO & 1994 & 2003 & First & $\begin{array}{l}\text { U-21 EURO 2013, U-20 FIFA WC 2009, U-17 FIFA WC 2007, U-19 EURO } \\
\text { 2006, UEFA CL, UEFA EL }\end{array}$ \\
\hline $\mathrm{R} 21^{*}$ & Alexey Kulbakov & BUL & 1995 & 2006 & First & U-19 EURO 2013, UEFA CL, UEFA EL \\
\hline R22 & Michael Oliver & ENG & 2000 & 2012 & First & U-19 EURO 2013, UEFA CL, UEFA EL \\
\hline R23 & Clément Turpin & FRA & 1996 & 2010 & First & U-19 EURO 2011, UEFA CL, UEFA EL \\
\hline
\end{tabular}

Note: *Test interviews; Rx, participant code; CL, Champions League; EL, Europe League; WC, World Cup.

ing qualitative empirical data. In the end, the interview guide comprehended, after a few "ice-breaker questions", the following sections: (1) demographics (e.g., "When did you start your career as a referee?"), (2) current problems (e.g., "What are the biggest problems or difficulties within refereeing nowadays?"), (3) team communication (e.g., "How does the communication within the referee team look like?"), and (4) decision-making training (e.g., "How do you practice your decision-making skills?"). Over the conduct of the interviews, depending on the responses of the participants, the order of the questions could be varied. Moreover, if the interviewer had the opinion to go deeper into the referee's point of view, detailed elaboration and clarification probes were used to gather deeper insights into the topic at hand (Patton, 2002). 


\section{Data collection}

After UEFA had provided permission to collect data, the first author contacted the referees who gave informed consent to participate in the study. The interviews were conducted at the $23^{\text {rd }}$ UEFA Advanced Course for Top Referees in February 2015 in Athens, Greece. All interviews were conducted in a quiet environment and under no time pressure. A verbal explanation of the study was given to each participant before the respective interviewee signed a declaration of informed consent in which it was pointed out that the participation is voluntary and that the shared information would remain anonymous unless explicit approval is given to cite certain passages of the interview verbatim by unravelling real names. Basically, English was the standard language for the interviews; however, as it was difficult for two referees to express themselves eloquently in English, these two interviews were held in German, which was spoken fluently by the interviewer as well. To increase consistency, all interviews were conducted by the first author, a football referee himself.

\section{Data analysis}

All interviews were recorded and then transcribed verbatim by the first author. The average length of the interviews was 19.4 $\min (S D=5.4 \mathrm{~min}$; range $=10.5-39.2 \mathrm{~min})$. To ensure the accuracy of the interview transcripts, each participant was sent his own interview as a transcribed copy via e-mail (Mayring, 2008). The vast majority of the referees declared to agree with the content and meaning, whereas three participants expanded, deleted, or added information to be completely reflected in their opinions.

Due to the focussed but exploratory character of the study, the transcriptions were analysed by inductive content analysis (Mayring, 2008) to avoid biased interpretations. To begin with, the first author and an independent coder studied the transcripts repeatedly to get used to the material. For the position of the independent coder, a non-expert regarding football refereeing was chosen to broaden the scope. After that, inductive content analysis was independently applied to mark words, phrases, or quotes. After an intensive discussion between the raters, the resulting raw-data themes formed the starting material for categorisation. After simplification of the raw-data themes in a generalisation step, four randomly selected interviews were categorized independently by the two raters. Based on these preliminary categorisations, lower-order themes were formed that were subsequently grouped into higher-order themes. On this basis, further five interviews were randomly selected and independently coded and the results discussed to further adjust the category framework. Finally, all the interviews were (re)analysed by the two coders. In cases of disagreements, the results were further discussed until consensus could be reached. The independent categorisation of the two coders ended up in an inter-rater reliability of $91.3 \%$.

\section{Results}

From the entire interview material, the data analysis resulted in 91 raw-data themes that were grouped into 22 lower-order themes and further structured into 7 higher-order themes, namely, (1) descriptive, (2) characteristics of a good elite referee, (3) difficulties in decision-making, (4) pre-match preparation, (5) communication through headset, (6) decision-making, and (7) decision-making training (see Figure 1). The report in Figure 1 adheres to this division into categories. In the following, the number of quotes within a category will be indicated in parentheses. As each quote was counted only once per participant, the maximum number of quotes would be 23. Germanheld statements were translated into English by the first author, and all the quotes were grammatically emended if necessary.

\section{Descriptive}

This higher-order theme regards personal information about the careers of the interviewees. It is subdivided into the following categories: reason to become a referee (22) and start of the career (18).

Reason to become a referee (22). This category represents the interviewees' motives to take the road of a football official. Most of the participants (17) mentioned that they previously played football and therefore already had a strong link with this sport: "As a young boy, I was a player. I played for Newcastle United in the academy, and my region, and my school, and my local team" (R22). Additionally, it was stated (11) that relatives or friends brought them to become referees: "One of the best friends of my brother was a referee and I was a player. But he convinced me to go to referee's school, and I started refereeing" (R08). Some interviewees also mentioned (4) that they started refereeing after an injury as a football player: "I played football and then with 15, I broke the leg during a training match. So, I recovered maybe half a year, and after that I was sitting on the bench, on the tribune. So, the coach asked me: Hey, you can try as a referee" (R21). The following reasons to become a referee were only mentioned once: money (1), self-confidence (1), and power (1).

Start of the career (18). Almost every participant highlighted his age of beginning with refereeing. On average, the referees were 15.0 years old $(S D=2.0$ years; range $=12-22$ years) when they started their vocation.

\section{Characteristics of a good elite referee}

This higher-order theme is concerned with the characteristics of a good elite referee. It is subdivided into the following categories: educability (21), game management qualities (21), mental attributes (18), fitness (18), personal characteristics (17), football intelligence (15), and experience (6).

Educability (21). This lower-order theme regards the learning ability as a characteristic of a good elite referee and describes a structured learning process in general. In this respect, many participants (15) mentioned the importance of having good 

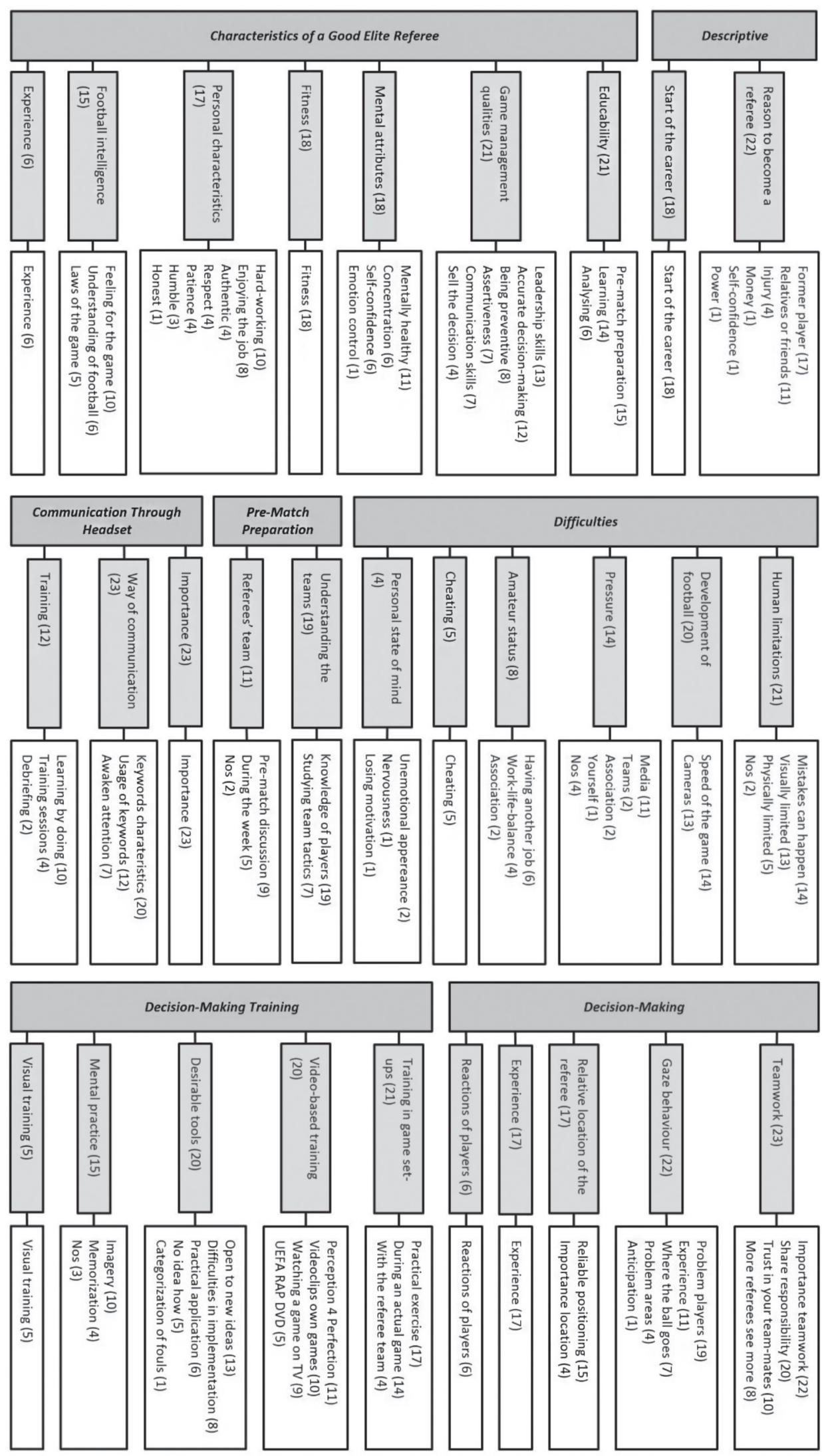

Figure 1: High-order themes (dark grey) with assigned lower-order themes (light grey) and raw-data themes. Note: The number of quotes is indicated in parentheses with a maximum count of 23; Nos=not otherwise specified. 
match routines, which includes "good preparation, not only physically but mentally; also preparing and seeing the tactics of the teams and being aware of the environment or the type of match you will be involved in" (R11). However, it was also said (14) that learning plays an important role in general: "We have to learn from every mistake we make. We have to learn from all the good things we do" (R04). Moreover, the importance of analysing own games was underlined (6): "It's very important, you have to watch your games back and develop your skills" (R10).

Game management qualities (21). Almost all referees referred to game management skills that are needed for being a good elite referee. In the context, the participants particularly underlined the importance of leadership skills (13), which means "to have the management skills and to be a manager of the game in order to facilitate the game; not to be a big star, but just to be able to facilitate players so the players can play the game" (R10). Furthermore, the role of accurate decision-making was highlighted (12): "Definitely, decision-making, accuracy of decisions must be $100 \%$. It's not possible to be $100 \%$, but we need to try to achieve $100 \%$ of accuracy of our decisions" (R20). Being preventive and proactive (8) was also counted as an important management skill to prevent the match from escalating: "Usually, if you prevent the incident, then you could prevent a lot of different things happening. And that's always my goal: You stop things from happening instead of being reactive" (R02). As a further aspect of an elite referee, assertiveness (7) was mentioned as the referee's capability to assert himself during a competitive match: "You have to punish it, you have to be strong" (R12). Moreover, having good communication skills seems to be vital (7): "In the pitches, communication is also so important because, if you know to communicate in a good way with the players, they will accept you" (R05). Finally, some of the referees pointed out that "selling" the decision (4) is a key point for excelling in game management: "A referee who sells the decision by being close and calm in language will get the call accepted" (R02).

Mental attributes (18). Another central characteristic of a good elite referee regards mental attributes. Thus, many participants mentioned the importance of being in an optimal mental condition (11): "You have to be mentally fit" (R04). The very same also applies to the ability to stay focussed (6): "Don't lose your concentration. It is the most important thing for referees" (R19). A further important mental attribute regards self-confidence (6): "First of all, personality is very important, and that you have a trust in yourself" (R04). Finally, one participant noticed that the control of emotion is fundamental (1): "For me, maybe the most important point is to have emotions under control" (R05).

Fitness (18). Not directly but indirectly related to psychological attributes of a good referee, the importance of fitness was highlighted because the quality of decision-making would be fundamentally impaired if the referee was in a considerably exhausted state. Hence, with respect to the overall acceleration of the game over the last decades, it nowadays seems to be crucial for an elite referee to be in a very good physical shape: "Fitness has become a huge and relevant component" (R18).
Personal characteristics (17). In contrast to the mental attributes described previously, this category refers to basic character traits that, by definition, cannot be changed in a short period of time. In this regard, many referees underlined that it is crucial to work hard on oneself to achieve top-level performance (10): "You cannot succeed in the long term if you're not hard working" (R03). Nevertheless, enjoying the challenge seems to be important as well (8): "I am a referee and I enjoy the job" (R14). Furthermore, a good referee should act authentically (4): "Every referee should have his own style. It's a mistake to be a copy of a top referee" (R21), show respect for other people as well as for himself (4): "Respect is to be a good referee, $1 / 4$ but at the same moment I want to have the same respect" (R15), and keep patience (4): "I didn't want to be quickly on the top. I just waited, I just watched, observed the good referees, and worked" (R01). Finally, being humble (3) and being honest (1) were mentioned as characteristics of a good referee.

Football intelligence (15). Within this category, many referees highlighted that a feeling for the game (10) as well as an understanding of football (6) is crucial: "But the biggest thing is for me: Referees have to understand football. They have to understand the culture and be able to put this into practice to manage a game safely" (R12). Moreover, some referees pointed explicitly out that knowing the laws of the game is inevitable (5): "Of course, you need to know the laws" (R22).

Experience (6). Finally, some of the referees also mentioned the importance of experience as a characteristic of a good referee, implying that it is necessary to "whistle" a lot: "I think it's about experience. I think experience makes you a good referee" (R11). As experience is not characterized by a structured learning process, respective statements were treated as belonging to a separate category rather than being included in the above sketched category educability.

\section{Difficulties in decision-making}

This higher-order theme regards the difficulties in decisionmaking that arise in the context of football refereeing. This theme can be broken down as follows: human limitations (21), development of football (20), pressure (14), amateur status (8), cheating (5), and personal state of mind (4).

Human limitations (21). The majority of the participants are convinced that there are certain human limitations on refereeing. Consequently, it was often mentioned that "errors can happen" (14): "I think being a human being, we are not perfect, so there will be mistakes and sometimes we just need to accept that" (R11). In this regard, many referees particularly referred to visual limitations, as it often seems to be a problem to perceive the situation clearly (13): "It's impossible to see everything" (R09). Besides perceptual issues, also physical limitations were reported by some referees (5): "Of course, you will have fatigue during the match, mental fatigue and physical fatigue. Your body will only do what it is able to do. You cannot be in two places at once" (R22).

Development of football (20). A problem for referees of today's football is the increasing speed of the game as, compared to 
earlier times, football has become extremely fast (14): "A problem is that, of course, the football nowadays is more and more fast, faster than in the previous. 1/4 So, now it's more typical that a player arrives to an action one second late. When they are late, only millisecond late, you never know, is it fault, or is it exaggeration by the player, or is it the situation. So, the limits are in a very, very thin line, more and more over the years" (R08). Another development of football regards the fact that there are many cameras directly on the sidelines around the pitch, such that errors of the referee can be better proven (13): "All problems, all wrong decisions, are becoming clear because you can see it on TV with three, four, five different angles and within half of a second you can see that you have made a mistake. That's the biggest problem, especially in professional football" (R03).

Pressure (14). One of the main difficulties for elite referees seems to be pressure, in particular, pressure from the media (11): "Especially, if you do matches in my country, it is very difficult because football is the most important thing for all the people and the media sometimes is very hard on the referees. I think this is the most difficult thing for referees: to deal with the media" (R19). Likewise, two referees feel also pressure from the teams (2) or from the football associations (2) in terms of "pressure of your organisation because each time you need to be more and more fit, each time you need to be more and more ready" (R07). In addition, one participant mentioned the pressure he typically puts on himself (1) as "pressure from yourself because we all want to do our best" (R20).

Amateur status (8). Within this category, different aspects of non-professionalism were reported. In this regard, having another job aside from being a referee is perceived as a severe problem (6): "Refereeing is not my main job, not a profession. I have my own business" (R21). To deal with issues regarding work-life balance was reported as a difficulty as well (4): "We are not full-time referees. So the balance between a full-time job, between my family life. I have very young children and also I'm refereeing. It can be difficult, you know" (R11). Finally, a few referees mentioned problems regarding their domestic association (2): "I think the lack of commitment from federations has a price to pay" (R02).

Cheating (5). A particular aspect that was pointed out with respect to difficulties was the players' tendency to deceive the referee (5): "Sometimes the players try to cheat the referee, especially in penalty area situations. It's one of the most difficult situations for us because sometimes the player falls down but you are not sure whether it's for penalty or no penalty because there are many players that, even by training, try to cheat the referee" (R07). Personal state of mind (4). Only a minority of referees referred to their own feelings as a potential issue within a match or over a season. In this regard, besides nervousness (1) or loss of motivation (1), it particularly seems to be difficult to hide personal emotions (2) during a competitive game: "In my opinion they should avoid emotions. 1/4 One player scores a goal and he removes his shirt. And it writes: No war, we want peace. But we have to show a yellow card for this player, because he removes his shirt. No emotions for the referees. Of course, I don't want to show a yellow card for this behaviour. But it writes on the laws of the game" (R01).

\section{Pre-match preparation}

Pre-match preparation as a higher-order theme describes the explicit prearrangement of the referees on an upcoming game. It is subdivided into two categories: understanding the teams (19) and referees' team (11).

Understanding the teams (19). This category refers to specific knowledge about the players and the teams that had been acquired in advance by pre-match preparation. In this regard, many participants brought up to by especially alerted by certain players' behaviours (19): "You need to know that number 7, for example, is always doing this. 1/4 Number 2 is always trying to grab one player or to hold or to push. So it's a lot about preparation, studying the players" (R09). Besides the players' behaviour, pre-match preparation also aims on becoming aware of the team tactics (7): "We try to study the teams, the way they make the corner kicks, the goal kicks, the free kicks. There is a lot of work that referees do just before the match" (R06).

Referees' team (11). Also, the preparation of the referees' own team is a vital aspect of a good pre-match preparation. Hence, many participants underlined the importance of an intensive group discussion a few hours before an upcoming game (9): "We talked about the teams, we talked about the strategies of the teams. One match for example: Maybe teams on top in the league or on bottom means different strategies. They have to win or the draw is enough for them. And it means they will play different" (R01). As well, some referees like to work with their assistants over the week for the sake of an optimal pre-match preparation (5): "When we were watching the Super Cup Final, I was in my WhatsApp Messenger group which I have with my team of six members holding this. $1 / 4$ We commented the game, we commented situations: Why did this happen, why did that happen? So this is also kind of preparation" (R20).

\section{Communication through headset}

Team communication through headset was brought up by all interviewees as a decisive factor for a good team performance. This higher-order theme can be broken down as follows: importance (23), way of communication (23), and training (12). Importance (23). All referees agreed that communication through headset is essential nowadays for achieving a good performance (23). Moreover, the participants could not imagine refereeing without a communication system anymore. Thus, it seems to be a vital support for the referees' team: " $t$ 's crucial. Sometimes I wonder how we could without it. If I did a match now where there was no communication system, I think I would find it quite off putting" (R11).

Way of communication (23). This category describes the style of the communication within the referees' team through the headset. In this regard, almost every referee stated to use keywords to communicate for a certain situation (20): "Very clear, 
short words, not whole sentences because then I lose it. Because there happens too much in the field. So very short: penalty, yellow card, number 40, free kick. Like keywords" (R04). Moreover, participants explained to use keywords in a specific manner (12). For instance, if the keyword is repeated only once, it should be understood just as a proposal. However, if the keyword is repeated three times, the referee should take the decision. Furthermore, the communication system is also used to bring the attention of the assistant referees to certain aspects of the situation (7): "So if the ball is close to them, I will tell them to be aware or careful. So they are focusing then" (R10).

Training (12). In the first instance, no special training is organised to acquire or optimise skills for communicating through the headset. Many participants pointed out that they picked it up just by practising (10) that means "mainly by doing. You have improved by your experience and learning and trying. You improve day by day" (R08). Only a few participants mentioned to practice their communication skills in specific training session (4): "Yes, we train that during the week, during our training sessions. We have a protocol with some guidelines, with some words that we use. All always the same, always the same. And try to give a short feedback, short words. That's the way to make good decisions" (R06). Two referees also referred to the match debriefing as a valuable training source (2): "We use a lot of work in the debriefing, how we communicate, how we manage, how we talk, which way we talk and so and so" (R14).

\section{Decision-making}

The higher-order theme of decision-making refers to the details of the process of coming up with an appropriate decision. This theme can be subdivided into the categories of teamwork (23), gaze behaviour (22), relative location of the referee (17), experience (17), and reactions of players (6).

Teamwork (23). To come up with a correct decision, teamwork appears to be crucial, as it was highlighted up by almost every participant (22): "We can help each other so much as a team and make the game easy for each of us" (R17). Moreover, many referees use to share responsibilities to manage a match precisely (20): "You are speaking with your team so that you share responsibility, particular inside the penalty area because it is impossible for you to see everything. So we have hope, we have trust with your colleagues. So, at that moment, you are fully concentrated on the ability to do what you are responsible for" (R10). In this context, trust seems to be a key aspect for successful teamwork (10): "I trust my team" (R04), as trust allows for a mutual enrichment of the decision-making process (8): "We have six pair of eyes and they look and see much better than two eyes" (R14).

Gaze behaviour (22). Gaze was mentioned by the vast majority of the referees as a crucial aspect of decision-making. Strategically, the participants mainly observe "problem players" during a set piece (19): "I always focus on the players. And if there are some problem players in the team I always focus them" (R01). In addition, various participants talked about the role of experience that is needed to focus the best location in certain match situations (11): "I think that comes from experience. When it comes to refereeing, you never know exactly where to look" (R02). In this regard, location anticipation due to ball-flight information seems to play an important role (7): "Every referee tries to put the focus where the ball goes" (R20). On the contrary, only a few referees prefer to observe certain problem areas during a set piece (4): "Of course you need to focus on where the incident started or the holding or the pushing or something like this" (R19). Moreover, just one referee (1) is convinced "about anticipation. If you can read the match very well, you can focus to the right place" (R01).

Relative location of the referee (17). To make a right decision, an adequate positioning of the referee in the field of play was often reported as a requirement for good decision-making (15): "Your wrong positioning can create a mess. It was a clear penalty, should be awarded and you don't see it because you are maybe only two meters to the right instead of two meters to the left" (R20). However, also the spot where an infringement occurs matters as, for example, a throw-in in the midfield is less relevant as a potential penalty situation (4): "The most important area of course is always the penalty area" (R07).

Experience (17). Overall experience was repeatedly pointed out as being crucial for a high quality of decision-making (17): "I believe, of course, in your experience. I think that when the referees do more matches, we are better. $1 / 4$ I feel better with more experience now than in the past. This is very important" (R19).

Reactions of players (6). When it comes to decision-making, a few referees also report to take the reaction of the players into account (6), referring to "the way that a player falls down to the ground; all the small details. The sensing, the reactions are very important for the referees to know what kind of decision we should take" (R06).

\section{Decision-making training}

The last higher-order theme refers to the training of the decision-making process. It is sectioned in five lower-order themes: training in game set-ups (21), video-based training (20), desirable tools (20), mental practice (15), and visual training (5).

Training in game set-ups (21). It is often tried to increase the quality of decision-making by training in game set-ups. In this exercising approach, young football players create different scenes (like foul situations near the penalty area, offside situations) and the referee or the referee team is supposed to judge them. Many participants reported to do those kinds of practical exercises (17), however, in total, no more than about twice per season: "It's very strange for me because in England, maybe two times in one season we would train with players" (R22). Instead, the referees mainly improve their decision-making skills during actual matches (14): "I do not train decision-making skills apart from the actual match" (R18). Just a few participants try to improve their decision-making skills together with their referee teams (4): "I'm sure that it is necessary. $1 / 4$ We check with the pictures and we check with the clips, but the most important thing if you want to improve is practice, practising of the situation as a team" (R23). 
Video-based training (20). Almost every referee makes use of video analyses to enhance his decision-making skills. In this respect, the most mentioned tool (11) is the web-based platform "Perception 4 Perfection" provided by the UEFA that covers specific situations from the additional assistant's point of view (goal/no goal, corner kicks, free kicks). Furthermore, the referees regularly analyse their own clips after a match (10): "To be honest, I analyse a lot after the game. 1/4 I analyse the match and, with my colleagues, we try to improve and be ready for the next game" (R05). But also just watching a game on TV is regarded as decision-making training by a lot of participants (9): "I think every day I train my decision-making skills because I watch other matches. I'm in the match myself, so we learn every day" (R04). In addition, the so-called "UEFA RAP" (Referee Assistance Program) DVD is used as a PC tool that is updated twice a season and contains different infringements that have to be judged in disciplinary (e.g., no card, yellow card, or red card) and technical respect (e.g., no foul, direct free kick, indirect free kick, or penalty kick) (5): "We have it with decisions and everything. And all considerations. So this is the guideline, this DVD is the guideline. So you need to apply this level of punishment, because this is decision of UEFA referee committee. So we need to try to achieve the same level" (R20).

Desirable tools (20). The vast majority of the participants underlined their desire for appropriate decision-making training tools. In this regard, about half of the referees would be very open to novel ideas (13): "Well, now I cannot say this or that, but generally, we need to be always open and not to close off" (R09). However, it was also pointed at difficulties in implementation, in particular with respect to reflect reality in training settings (8), because "if a player has to act a situation that rarely comes close to a real situation" (R18). Nevertheless, a few referees agree that more practical training should be introduced (6): "I think the information in the Internet is fantastic but I think more training on the field would be even better" (R22). Regarding off-field practice, participants are generally in doubt how a supportive tool might look like (5): "I don't know in which way, but I think it's interesting" (R21). Just one referee came up with the explicit suggestion to develop a tool that would be based on a categorisation of specific movement patterns for detecting the seriousness of a foul play (1).

Mental practice (15). Mental practice was reported to be an important aid for improving decision-making in refereeing. In particular, the participants use the method of imagery (10): "I put some cones on the pitch and I imagine a situation with players. $1 / 4$ I run. I speak aloud, I imagine, I speak to my assistant referee or my additional referee and I say: Okay, for me it's a penalty; are you okay? Or this is a defender who touched the ball for an offside situation maybe" (R23). Another approach to mental practice mentioned by some interviewees regards memorisation (4): "We will have something to remember, to repeat, to take a correct photo $1 / 4$ and always to make new photos inside your head $1 / 4$ what happens in a match" (R14).

Visual training (5). Some participants also reported to rely on non-specific visual training to improve decision-making perfor- mance (5): "When we do the visual test, they give us good kinds of exercises. So even if you are sitting at a traffic light you are able to think wider than just here, just between your brain and your eyes. To be able to think much further, just looking at you I can see what's going on here or what's going on there" (R11).

\section{Discussion}

In recent times, sports officiating research has increasingly acknowledged the importance of the psychological facets of sports refereeing (MacMahon et al., 2014). Because the majority of the football-related studies pursued a "from theory to practice" approach, the aim of the current investigation was to evaluate the officiating problem as they surface on "real-world" practice such that the study has been based on qualitative interviews with top-level football referees. Overall, seven higherorder themes were raised by the participating European elite referees. Apart from a descriptive category (e.g., reason to become a referee), various characteristics of a good elite referee were noted: educability, game management qualities, mental attributes, fitness, personal characteristics, football intelligence, and experience. Furthermore, today's problems for referees in football were specified with respect to human limitations, development of football, pressure, amateur status, cheating of players, and personal state of mind. Moreover, pre-match preparation (understanding the teams, referee's team) and communication through headset (importance, way of communication, training) seem to be crucial aspects for a successful performance. In addition, the participants mentioned essential points for the quality of decision-making. In this context, teamwork, gaze behaviour, the relative location of the referee, experience, and reactions of players seem to play a vital role in taking decisions on the field of play. Regarding the question how the referees train these aspects, the responses can be grouped into training within game set-ups, video-based training, wishes for desirable tools, mental practice, and visual training.

What do these findings mean for the science of football refereeing? First of all, it becomes obvious that a number of practical aspects mentioned in the interviews have already been discussed widely in science as sketched in the introduction to this paper. Above all, the research branch of visual perception within football refereeing is well recognised by the elite referees. From a practical point of view, video-based training tools, such as Helsen's "Perception 4 Perfection", are considered helpful for improving decision-making skills, thus reflecting scientific evaluations (e.g., Put et al., 2015; Schweizer et al., 2011). Furthermore, science is giving attention to details of the visual skills of officials and to the question to what degree these skills could form a limiting factor in the decision-making process. This idea is also reflected by the referees who particularly pointed out the importance of a reliable positioning during a match. In addition, watching games passively is acknowledged as a tool to improve decision-making quality by practitioners as well as by scientists (Pizzera \& Raab, 2012b). Consequently, based 
on those overlaps between scientific research and its subjective relevance reported by the referees, it can be concluded that research focussing on visual perception and respective performance enhancement can be considered as a particular practice-relevant research area.

In contrast, as described in the Introduction, a large proportion of studies that have been published within football officiating research focus on bias-related issues, for instance, regarding the question whether cues, such as crowd noise (Dohmen, 2008; Downward \& Jones, 2007; Nevill et al., 2002; Page \& Page, 2010; Unkelbach \& Memmert, 2010) colours of the shirts (Frank \& Gilovich, 1988), or a player's reputation (Jones, Paull \& Erskine, 2002), have an effect on the decision-making process. Essentially, this subject has not been addressed by the referees at all. On the one hand, this mismatch can be discussed in such a way that the actual importance of biases is not realised by the referees, implying that some effort of convincing the practitioners would be needed at least. On the other hand, the mismatch might be taken as a hint that the actual importance of biases is overestimated in sport science. As a matter of course, based on the data at hand, it cannot be decided which of these conflicting interpretations should be favoured over the other one. What, however, can be concluded at least is that the mismatch point is an issue that should be considered in future research on football officiating.

Moreover, a comparison between scientific publications and the referees' view on officiating in football reveals a second kind of mismatch, namely, in those cases when points were raised by the practitioners, which have not been addressed in science so far. From the referees' subjective perspective, those points refer to the biggest problem areas within refereeing in the real world of practice.

(1) Almost all referees regularly analyse the teams in the prematch preparation. In this context, especially the explicit analysis of an individual players' behaviour seems to be central. This preparation, however, comes along with the danger of distorted decisions due to prejudice, as it is expressed by the American Sport Education Program (2011, pp. 96-97) as follows: “On the surface it would seem that the more information you have, the better prepared you will be. The dangerous flip side is letting the information you've gathered negatively influence the way you handle a situation." For this reason, it would be valuable to support the referees by scientifically evaluated tools that, on the one hand, facilitate the analysis of individual players' behaviour or of tactical action patterns of both teams and, on the other hand, sensitise the referees for certain dangers of distorted decisions.

(2) Almost every official stated that human limitations need to be taken into account and that these limitations have become more obvious as a result of recent developments in football. As the game gets faster and faster, it is increasingly difficult for the referees to keep up with the play and to visually detect the infringements appropriately. These problems automatically entail questions on technical support for sport officials. Although FIFA has recently allowed goal-line technologies, football is still difficult with the implementation of technical aids, as the high costs of setting up and maintenance of the technical equipment could also be directly invested in an improved education of referees (in cricket: Borooah, 2013). In the context of this debate, a scientifically substantiated knowledge about technical aids would be of great help.

(3) In regard to performance enhancement, the majority of referees is very open to novel training tools. In this regard, two specific issues have been highlighted: difficulties in making an exercise as realistic as possible and problems referring to the practical applicability. For both issues, virtually no scientific research can be found that aims on the development of respective tools as such or on the experimental investigation of the underlying assumption of positive transfer from the training environment to the on-field situation (e. g. Put et al., 2013). In the future, taking decisions under pressurised conditions in a virtual-reality environment could be a way forward; however, a respective foundation and evaluation by scientific research would be desired.

(4) As in European top games six officials are appointed (one head referee, two assistant referees, one fourth official, and two additional assistant referees), it was underlined by a lot of interviewees that teamwork plays an important role. In this regard, referees mentioned to share their responsibility on the field of play to come up with the most appropriate decision. In particular, communication through headset is considered very important, although communication details, for instance, regarding the use of keywords are fixed mainly based on learning by doing. At this point, it is dissatisfying that research on the optimisation of this communication is completely missing so far as a more effective collaboration within the referees' team would certainly lead to more accurate decisions.

(5) In the interviews, many officials indicated that they are exercising mentally. Particularly, imagery seems to offer a vast potential to better deal with the mental stress and with technical aspects as well. Hence, a further interesting research field would open up aiming on the derivation of specific recommendation for mental practicing game situations in top-level football. Those investigations might be of particular value if they were conducted as fieldwork in close collaboration between a referee team and a personal psychologist.

A strength of the present study, as we believe, is the sample of European elite football referees. Since all participants are regularly in charge of UEFA Champions League games, they are among the best football officials worldwide. Thus, interviewing these referees has provided us with a unique insight into current issues in football refereeing. As a matter of course, it needs to be considered that these insights are based on a reconstruction of subjective impressions. Hence, the statements do not necessarily reflect actual realities and should be rather taken as explications of what top-level football referees think about themselves - or how they would like to think about themselves. Nevertheless, a qualitative approach provides a great way to explore exactly those kinds of subjective reflections and may thus be taken as a starting point for quantitative hypothesis- 
driven analyses. Having said this, we would like to claim that our qualitative reconstructions adds value to the scientific discussion on officiating in sports.

To sum up, the aim of the study was to identify problem areas in the practice of top-level football refereeing. To not restrict the outcome in advance by theory-driven boundaries, a qualitative button-up approach was chosen. An inductive categorisation of the raw interview material resulted in seven higher-order themes, namely, descriptive, characteristics of a good elite referee, difficulties in decision-making, pre-match preparation, communication through headset, decision-making, and decision-making training. The comparison of the subjective relevant issues to the findings revealed by scientific research on football officiating showed that the vast researched area of visual capabilities and perception enhancement is also recognised by the interviewees as highly relevant. In contrast, a number of publications can be found on the effects of potential biases on decision-making, whereas biases were not mentioned by the referees as an important issue affecting their decisionmaking. A clear need for further research, however, could be revealed for those topics, which, due to the statements of the interviewees, are, on the one hand, highly relevant from a practical perspective but for which, on the other hand, only a small amount or even no scientific investigations can be found so far. These topics refer to the optimisation of the pre-match preparation, the evaluation of supporting technical devices, the development of innovative training tools for improving the decision-making quality, the optimisation of the communication within the referee team, particularly through the headset, and the evaluation of supporting training methods such as mental practice. Hence, for sport scientists with a special interest in applied work, these topics are recommended for conducting further research.

\section{Acknowledgements}

The authors thank the UEFA and Luzia Porret for the administrative assistance relating to the interviews, all the participating referees, and Simona Götz for the support in the process of data analysis.

\section{Funding}

This work was supported by a grant provided by the Swiss Football Association.

\section{Competing Interests}

The authors have declared that no competing interests exist.

\section{Data Availability Statement}

All relevant data are within the paper.

\section{References}

American Sport Education Program (2011). Successful sports officiating (2nd ed.). Champaign, IL: Human Kinetics.

Baldo, M. V. C., Ranvaud, R. D., \& Morya, E. (2002). Flag errors in soccer games: The flash-lag effect brought to real life. Perception, 31, 1205-1210. doi: 10.1068/p3422

Bard, C., Fleury, M., Carrière, L., \& Hallé, M. (1980). Analysis of gymnastics judges' visual search. Research Quarterly for Exercise and Sport, 51, 267-273. doi: 10.1080/02701367.1980.10605195

Barte, J., \& Oudejans, R. (2012). The effects of additional lines on a football field on Assistant referees' positioning and offside Judgments. International Journal of Sports Science and Coaching, 7, 481-492. doi: 10.1260/1747-9541.7.3.481

Borooah, V. K. (2013). Upstairs and downstairs: The imperfections of cricket's decision review system. Journal of Sports Economics. Epub ahead of print. doi: 10.1177/1527002513511973

Boyko, R. H., Boyko, A. R., \& Boyko, M. G. (2007). Referee bias contributes to home advantage in English premiership football. Journal of Sports Sciences, 25, 1185-1194. doi: 10.1080/02640410601038576

Brand, R., Schweizer, G., \& Plessner, H. (2009). Conceptual considerations about the development of a decision making training method for expert soccer referees. In D. Araújo, H. Ripoll, \& M. Raab (Eds.), Perspectives on cognition and action in sport (pp. 181-190). Hauppauge, NY: Nova Science.

Buraimo, B., Forrest, D., \& Simmons, R. (2010). The 12th man? Refereeing bias in English and German soccer. Journal of the Royal Statistical Society A, 173, 431-449. doi: 10.1111/j.1467985X.2009.00604.x

Castagna, C., Abt, G., \& D'Ottavio, S. (2007). Physiological aspects of soccer refereeing performance and training. Sports Medicine, 37, 625-646. doi: 10.2165/00007256-200737070-00006

Catteeuw, P., Gilis, B., García-Aranda, J. M., Tresaco, F., Wagemans, J., \& Helsen, W. (2010). Offside decision making in the 2002 and 2006 FIFA World Cups. Journal of Sports Sciences, 28, 1027-1032. doi: 10.1080/02640414.2010.491084

Catteeuw, P., Gilis, B., Jaspers, A., Wagemans, J., \& Helsen, W. (2010). Training of perceptual-cognitive skills in offside decision making. Journal of Sport \& Exercise Psychology, 32, 845-861.

Catteeuw, P., Gilis, B., Wagemans, J., \& Helsen, W. (2010a). Offside decision making of assistant referees in the English Premier League: Impact of physical and perceptual-cognitive factors on match performance. Journal of Sports Sciences, 28, 471-481. doi: 10.1080/02640410903518184

Catteeuw, P., Gilis, B., Wagemans, J., \& Helsen, W. (2010b). Perceptual-cognitive skills in offside decision making: Expertise and training effects. Journal of Sport \& Exercise Psychology, 32, 828844. 
Catteeuw, P., Helsen, W., Gilis, B., Van Roie, E., \& Wagemans, J. (2009). Visual scan patterns and decision-making skills of expert assistant referees in offside situations. Journal of Sport \& Exercise Psychology, 31, 786-797.

Cunningham, I., Mellick, M., Mascarenhas, D., \& Fleming, S. (2012). Decision-making and decision communications in elite rugby union referees: An inductive investigation. Sport \& Exercise Psychology Review, 8, 23-34.

Dawson, P., \& Dobson, S. (2010). The influence of social pressure and nationality on individual decisions: Evidence from the behaviour of referees. Journal of Economic Psychology, 31, 181191. doi: 10.1016/j.joep.2009.06.001

Dawson, P., Dobson, S., Goddard, J., \& Wilson, J. (2007). Are football referees really biased and inconsistent? Evidence on the incidence of disciplinary sanction in the English Premier League. Journal of the Royal Statistical Society A, 170 (1), 231-250.

Dohmen, T. J. (2008). The influence of social forces: Evidence from the behavior of football referees. Economic Inquiry, 46, 411-424. doi: 10.1111/j.1465-7295.2007.00112.x

Downward, P., \& Jones, M. (2007). Effects of crowd size on referee decisions: Analysis of the FA Cup. Journal of Sports Sciences, 25, 1541-1545. doi: 10.1080/02640410701275193

Frank, M. G., \& Gilovich, T. (1988). The dark side of self- and social perception: Black uniforms and aggression in professional sports. Journal of Personal Social Psychology, 54, 74-85. doi: 10.1037/0022-3514.54.1.74

Ghasemi, A., Momeni, M., Jafarzadehpur, E., Rezaee, M., \& Taheri, H. (2011). Visual skills involved in decision making by expert referees. Perceptual \& Motor Skills, 112, 161-171. doi: 10.2466/05.22.24.27.PMS.112.1.161-171

Ghasemi, A., Momeni, M., Rezaee, M., \& Gholami, A. (2009). The difference in visual skills between expert versus novice soccer referees. Journal of Human Kinetics, 22, 15-20. doi: 10.2478/ v10078-009-0018-1

Gilis, B., Helsen, W., Catteeuw, P., Van Roie, E., \& Wagemans, J. (2009). Interpretation and application of the offside law by expert assistant referees: Perception of spatial positions in complex dynamic events on and off the field. Journal of Sports Sciences, 27, 551-563. doi: 10.1080/02640410802702178

Gilis, B., Helsen, W., Catteeuw, P., \& Wagemans, J. (2008). Offside decisions by expert assistant referees in association football: Perception and recall of spatial positions in complex dynamic events. Journal of Experimental Psychology: Applied, 14, 21-35. doi: 10.1037/1076-898X.14.1.21

Goumas, C. (2014). Home advantage and referee bias in European football. European Journal of Sport Science, 14, S243-S249. doi: 10.1080/17461391.2012.686062

Helsen, W., \& Bultynck, J. B. (2004). Physical and perceptualcognitive demands of top-class refereeing in association football. Journal of Sports Sciences, 22, 179-189. doi: 10.1080/02640410310001641502

Helsen, W., Gilis, B., \& Weston, M. (2006). Errors in judging "offside" in association football: Test of the optical error versus the perceptual flash-lag hypothesis. Journal of Sports Sciences, 24, 521 528. doi: 10.1080/02640410500298065
Johnston, R. (2008). On referee bias, crowd size, and home advantage in the English soccer premiership. Journal of Sports Sciences, 26, 563-568. doi: 10.1080/02640410701736780

Jones, M. V., Paull, G. C., \& Erskine, J. (2002). The impact of a team's aggressive reputation on the decisions of association football referees. Journal of Sports Sciences, 20, 991-1000. doi: 10.1080/026404102321011751

Krustrup, P., Helsen, W., Randers, M. B., Christensen, J. F., MacDonald, C., Rebelo, A. N., \& Bangsbo, J. (2009). Activity profile and physical demands of football referees and assistant referees in international games. Journal of Sports Sciences, 27, 1167-1176. doi: 10.1080/02640410903220310

MacMahon, C., Helsen, W. F., Starkes, J. L., \& Weston, M. (2007). Decision-making skills and deliberate practice in elite association football referees. Journal of Sports Sciences, 25, 65-78. doi: 10.1080/02640410600718640

MacMahon, C., Mascarenhas, D., Plessner, H., Pizzera, A., Oudejans, R., \& Raab, M. (2014). Sports officials and officiating: Science and practice. London: Routledge.

MacMahon, C., \& Plessner, H. (2008). The sport official in research and practice. In D. Farrow, J. Baker, \& C. MacMahon (Eds.), Developing sport expertise (pp. 172-192). London: Routledge.

MacMahon, C., \& Plessner, H. (2013). The sport official in research and practice. In C. MacMahon, D. Farrow \& J. Baker (Eds.), Developing sport expertise - Researchers and coaches put theory into practice (pp. 71-95). London: Routledge.

Mallo, J., Frutos, P. G., Juárez, D., \& Navarro, E. (2012). Effect of positioning on the accuracy of decision making of association football top-class referees and assistant referees during competitive matches. Journal of Sports Sciences, 30, 1437-1445. doi: 10.1080/02640414.2012.711485

Mascarenhas, D. R. D., Collins, D., \& Mortimer, P. (2005). Elite refereeing performance: Developing a model for sport science support. Sport Psychologist, 19, 364-379.

Mascarenhas, D. R. D., O'Hare, D., Plessner, H., \& Button, C. (2006). The psychological and performance demands of association football refereeing. International Journal of Sport Psychology, 37, 99-120.

Mason, C., \& Lovell, G. (2000). Attitudes, expectations and demands of English Premier League football association referees. Football Studies, 3, 88-102.

Mayring, P. (2008). Qualitative Inhaltsanalyse: Grundlagen und Techniken [Qualitative content analysis: Basics and techniques]. Weinheim, Germany: Beltz.

Mellick, M. C., Fleming, S., Bull, P., \& Laugharne, E. J. (2005). Identifying best practice for referee decision communication in association and rugby union football. Football Studies, 8, 42-57.

Mellick, M., Fleming, S., \& Davies, G. (2007). An interpretive analysis of interpersonal communication: A case study from elite rugby union match officiating. International Journal of Performance Analysis in Sport, 7(2), 92-105.

Nevill, A. M., Balmer, N. J., \& Williams, A. M. (2002). The influence of crowd noise and experience upon refereeing decisions in football. Psychology of Sport and Exercise, 3, 261-272. doi: 10.1016/ S1469-0292(01)00033-4 
Oliveira, M. C., Orbetelli, R., \& Barros Neto, T. L. (2011). Call accuracy and distance from the play: A study with Brazilian soccer referees. International Journal of Exercise Science, 4, 30-38.

Oudejans, R. R., Bakker, F. C., Verheijen, R., Gerrits, J. C., Steinbrückner, M., \& Beek, P. J. (2005). How position and motion of expert assistant referees in soccer relate to the quality or their offside judgements during actual match play. International Journal of Sport Psychology, 36, 3-21.

Oudejans, R. R., Verheijen, R., Bakker, F. C., Gerrits, J. C., Steinbrückner, M., \& Beek, P. J. (2000). Errors in judging "offside" in football. Nature, 404, 33. doi: 10.1038/35003639

Page, K., \& Page, L. (2010). Alone against the crowd: Individual differences in referees' ability to cope under pressure. Journal of Economic Psychology, 31, 192-199. doi: 10.1016/j.joep.2009.08.007

Patton, M. Q. (2002). Qualitative research and evaluation methods (2nd ed.). London: Sage.

Philippe, F. L., Vallerand, R. J., Andrianarisoa, J., \& Brunel, P. (2009). Passion in referees: Examining their affective and cognitive experiences in sport situations. Journal of Sport \& Exercise Psychology, 31, 77-96.

Pizzera, A., \& Raab, M. (2012a). Does motor or visual experience enhance the detection of deceptive movements in football? International Journal of Sports Science and Coaching, 7, 269-283. doi: 10.1260/1747-9541.7.2.269

Pizzera, A., \& Raab, M. (2012b). Perceptual judgments of sports officials are influenced by their motor and visual experience. Journal of Applied Sport Psychology, 24, 59-72. doi: 10.1080/10413200.2011.608412

Plessner, H., \& Betsch, T. (2001). Sequential effects in important referee decisions: The case of penalties in soccer. Journal of Sport \& Exercise Psychology, 23, 254-259.

Plessner, H., \& Haar, T. (2006). Sports performance judgments from a social cognitive perspective. Psychology of Sport \& Exercise, 7, 555-575. doi: 10.1016/j.psychsport.2006.03.007

Plessner, H., \& MacMahon, C. (2013). The sport official in research and practice. In D. Farrow, J. Baker, and C. MacMahon (Eds.), Developing sport expertise: Researchers and coaches put theory into practice (pp. 71-95). London: Routledge.

Plessner, H., \& Schallies, E. (2005). Judging the cross on rings: A matter of achieving shape constancy. Applied Cognitive Psychology, 19, 1145-1156. doi: 10.1002/acp.1136

Put, K., Wagemans, J., Jaspers, A., \& Helsen, W. F. (2013). Web-based training improves on-field offside decision-making performance. Psychology of Sport and Exercise, 14, 577-585. doi: 10.1016/j.psychsport.2013.03.005

Put, K., Wagemans, J., Spitz, J., Williams, A. M., \& Helsen, W. F. (2015). Using web-based training to enhance perceptual-cognitive skills in complex dynamic offside events. Journal of Sports Sciences. Epub ahead of print. doi: 10.1080/02640414.2015.1045926
Renden, P. G., Kerstens, S., Oudejans, R. R., \& Cañal-Bruland, R. (2014). Foul or dive? Motor contributions to judging ambiguous foul situations in football. European Journal of Sport Science, 14, S221-S227. doi: 10.1080/17461391.2012.683813

Schnyder, U., Koedijker, J., Kredel, R., \& Hossner, E.-J. (2014). Gaze behaviour in offside decision-making in football: A field study. 1st International Conference in Science and Practice of Sports Refereeing. Clermont-Ferrand; self-published.

Schwarz, W. (2011). Compensating tendencies in penalty kick decisions of referees in professional football: Evidence from the German Bundesliga 1963-2006. Journal of Sports Sciences, 29, 441-447. doi: 10.1080/02640414.2010.538711

Schweizer, G., Plessner, H., Kahlert, D., \& Brand, R. (2011). A videobased training method for improving soccer referees' intuitive decision-making skills. Journal of Applied Sport Psychology, 23, 429-442. doi: 10.1080/10413200.2011.555346

Slack, L. A., Maynard, I. W., Butt, J., \& Olusoga, P. (2013). Factors underpinning football officiating excellence: Perceptions of English Premier League referees. Journal of Applied Sport Psychology, 25, 298-315. doi: 10.1080/10413200.2012.726935

Sutter, M., \& Kocher, M. G. (2004). Favoritism of agents. The case of referees' home bias. Journal of Economic Psychology, 25, 461469. doi: 10.1016/S0167-4870(03)00013-8

Unkelbach, C., \& Memmert, D. (2008). Game management, context effects, and calibration: The case of yellow cards in soccer. Journal of Sport \& Exercise Psychology, 30, 95-109.

Unkelbach, C., \& Memmert, D. (2010). Crowd noise as a cue in referee decisions contributes to the home advantage. Journal of Sport \& Exercise Psychology, 32, 483-498.

Weston, M., Castagna, C., Helsen, W., \& Impellizzeri, F. (2009). Relationships among field-test measures and physical match performance in elite-standard soccer referees. Journal of Sports Sciences, 27, 1177-1184. doi: 10.1080/02640410903110982

Whitney, D., Wurnitsch, N., Hontiveros, B., \& Louie, E. (2008). Perceptual mislocalization of bouncing balls by professional tennis referees. Current Biology, 18, R947-R949. doi: 10.1016/j. cub.2008.08.021

Wolfson, S., \& Neave, N. (2007). Coping under pressure: Cognitive strategies for maintaining confidence among soccer referees. Journal of Sport Behavior, 30, 232-247.

Yavuz, M., İnan, U. H., \& Fiğlalı, A. (2008). Fair referee assignments for professional football leagues. Computers \& Operations Research, 35, 2937-2951. doi: 10.1016/j.cor.2007.01.004 